\title{
TERRITORIOS DISCURSIVOS DEL PUEBLO MAPUCHE-WILLICHE
}

\section{DISCURSIVE TERRITORIES OF THE MAPUCHE-WILLICHE PEOPLE}

\author{
Sandra Villanueva-Gallardo*
}

\begin{abstract}
El siguiente trabajo tiene por objetivo dilucidar los territorios discursivos (TD) presentes en los discursos territoriales del pueblo mapuche-williche. Para ello nos centraremos en las narrativas desarrolladas por comunidades williche originarias del sur de Chile, cuya extensión geográfica ha sido históricamente conocida como Fütawillimapu (gran territorio sur).

Proponemos la elucidación de los sentidos territoriales e identitarios negados por la visión hegemónica occidental, mediante la configuración de las imágenes hologramáticas colectivas que emergen de estos discursos.

Por medio de la interpretación hermenéutica, analizaremos los relatos orales, escritos e iconográficos desde tres ángulos discursivos: 1) estético-cultural 2) político-ancestral y 3) político-representativo.

Los principales resultados que arroja la investigación están vinculados a cuatro dimensiones territoriales que caracterizan a los TD, otorgándoles: 1) visualidad 2) sonidos 3) símbolos y 4) fronteras, posibilitando una comprensión distinta de los límites y conformaciones identitarias actuales.
\end{abstract}

Palabras claves: Territorios discursivos, imaginario, holograma, epistemología.

The following work aims to elucidate the discursive territories (TD) present in the territorial discourses of the Mapuche-Williche people. To do this we will focus on the narratives developed by Williche communities originating in southern Chile, whose geographical extension has historically been known as Fütawillimapu (great southern territory).

We propose the elucidation of the territorial and identity senses denied by the western hegemonic vision, through the configuration of the collective hologram images that emerge from these discourses.

Through hermeneutical interpretation we will analyze oral, written and iconographic accounts from three discursive angles: 1) aesthetic-cultural 2) political-ancestral and 3) political-representative.

The main results of the research are linked to four territorial dimensions that characterize TD, giving them: 1) visuality 2) sounds 3) symbols and 4) borders, enabling a different understanding of current identity boundaries and conformations.

Key words: Discursive territories, imaginary, hologram, epistemology.

\section{Introducción}

El territorio puede ser analizado y comprendido desde distintos marcos semánticos y pragmáticos que lo posicionan como un concepto, una categoría o como un proceso. En todos los casos se producen complejas distinciones que lo sitúan en un espacio en permanente disputa epistemológica. Desde este punto de partida, la discusión territorial en Chile se ubica en un plano de conflicto sociopolítico, siendo un claro ejemplo de ello la histórica confrontación entre el Estado chileno y el pueblo mapuche.

Esta discusión lleva décadas de análisis, realizados por múltiples voces tanto desde el ámbito social, político y académico, por lo que existe un vasto caudal de interpretaciones respecto de los procesos de migración forzada o diáspora mapuche (Marimán 1997; Antileo 2015), acerca de la denominada intelectualidad indígena (Zapata 2005), sobre los procesos de desterritorialización llevados por el estado colonial (Nahuelpán 2012; Pinto 2015), en torno a la relevancia de los discursos poéticos mapuche (García 2006; Park 2007), en cuanto a la orgánica interna en respuesta al racismo de Estado (Pairican 2015; Coordinadora Arauco Malleco [CAM] 2019), alrededor de la espiritualidad conectada a los territorios (Bacigalupo 1997; Tricot 2013) y de la historicidad negada en los procesos de despojo (Mallon 2004; Cayuqueo 2017; Calfío 2017). En fin, el listado es mucho mayor del que puedo sintetizar en este espacio, por lo que solo quiero reconocer que este estudio recoje aspectos expuesto por dichos autores y sus líneas de investigación, haciendo hincapié en mi preferencia en cómo ellos/as han abordado las dimensiones políticas del conflicto entre el Estado y el pueblo mapuche.

Me refiero a que uno de los enfoques fundamentales en el análisis es lo que denominamos choque

* Universidad de Los Lagos. Osorno, Chile. Correo electrónico: villanuevagallardo@gmail.com 
epistemológico entre distintas concepciones acerca del territorio y la naturaleza, pues lo que allí confluye es una confrontación entre el Estado chileno, la élite política-económica y el pueblo mapuche (Clavería et al. 2020). Esto sucede porque históricamente la institucionalidad estatal ha defendido los intereses económicos de una élite intensamente imbricada al poder político chileno, la que lleva consigo una visión extractivista de la naturaleza como un recurso susceptible de ser explotado sin restricciones, pasando por encima de las comunidades indígenas que han habitado ancestralmente estos territorios (Vergara y Mellado 2018). Como consecuencia, los pueblos originarios se encuentran en oposición a la visión estatal, apelando a elementos integrados de valoración y respeto por la tierra y su capacidad como sujeto vivo. En este sentido, creemos que la elucidación de otras formas de estudio y comprensión de los espacios y lugares, se hace una tarea imprescindible para propender puntos de encuentro entre culturas diversas (Quintriqueo y Arias-Ortega 2019), donde efectivamente se visibilicen los sentidos profundos conectados entre el habitante y su territorio.

Con esta finalidad, la investigación se centrará en abordar las siguientes preguntas: ¿Qué caracteriza a un territorio discursivo en tanto territorio otro? ¿Cuáles son las particularidades de los territorios discursivos mapuche-williche en la actualidad?

\section{Metodología}

Los TD son una propuesta teórica-metodológica que por medio del análisis hermenéutico de las emociones, la memoria colectiva y los mapas mentales expuestos mediante los discursos, develan las imágenes hologramáticas ${ }^{1}$ soterradas por las actuales geografías hegemónicas del Occidente moderno.

Los fundamentos epistemológicos que hacen viable esta estrategia territorial están asentados en ocho principios claves (Villanueva-Gallardo 2018) para la interpretación de los sentidos identitarios que hacen a un sujeto/a social referirse de determinada forma acerca de su territorio ${ }^{2}$.

Uno de los aspectos centrales de los TD corresponde a dos intersecciones metodológicas sugeridas para su análisis. La primera trata de dos elementos fundamentales: las líneas de fuga (Guattari 2013) expresadas por medio de las afectividades territoriales (Tuan 1974) -ya sean muestras de amor, apego, desapego, indiferencia-, y la memoria colectiva de los sujetos pertenecientes a un grupo, comunidad o pueblo, donde se proyecta la develación del sentido territorial de estos discursos.

La segunda etapa refiere a la configuración del holograma territorial. Ello se realiza a partir del sentido de identidad analizado en la primera intersección, proyectando las imágenes colectivas que emergen en torno al territorio. Algunas de las herramientas empleadas para este objetivo son la utilización de mapas mentales, dibujos y cartografías colectivas. A partir de este punto, proponemos el análisis y elucidación de cuatro estructuras imaginarias presentes en todo tipo de TD, las que hemos sintetizado en los siguientes ámbitos: 1) visual 2) auditivo 3) simbólico y 4) frontera.

El desarrollo de estas etapas busca interpretar los TD del pueblo mapuche-williche para coadyuvar a un mejor entendimiento de la pluralidad territorial. Por tanto, es relevante para esta investigación el carácter territorial que adquieren los elementos simbólicos, los que han sido relegados a un ámbito secundario o exclusivamente imaginario, mal entendido como ficticio.

Para el objetivo propuesto nos basamos en distintos registros obtenidos mediante tres procesos diferentes de aproximación a la visión territorial mapuche-williche: a) entrevistas y talleres con escritores williche; b) entrevistas en profundidad con logkos williche, y c) análisis de las actas del proceso constituyente indígena-acción propiciada por el Ministerio de Desarrollo Social en el 2016, donde participaron cerca de cien representantes williche de la isla de Chiloé-.

La selección de este corpus textual estuvo mediada por criterios que respondieran a sujetos representativos del quehacer cultural y político ancestral de la Fütawillimapu ${ }^{3}$. Asimismo, nuestro interés fue también abordar un criterio estético-cultural ${ }^{4}$ con la presencia de nueve escritores mapuchewilliche reconocidos por su amplia calidad literaria y su vasto conocimiento de la cultura originaria. Nos referimos a Sonia Caicheo, Jaime Huenún, Faumelisa Manquepillán, Miriam Torres Millán, Javier Milanca, Graciela Huinao, Roxana Miranda Rupailaf, Bernado Colipán y Cristián Antillanca.

Abordamos el criterio de selección y análisis político-ancestral recurriendo a entrevistas en profundidad con logkos williche, ya que por su rol político dentro de las comunidades y por la autoridad que representan, se convierten en sujetos de conocimiento relevantes para la elucidación de los TD pertenecientes a esta cultura. De esta 
manera, incorporamos los discursos territoriales de los logkos Carlos Paillamanque y Arturo Camiao, ambos autoridades tradicionales de la comuna de San Juan de la Costa ${ }^{5}$.

Finalmente, optamos por el análisis discursivo del registro escrito de las actas del proceso constituyente indígena, pues en ellas se plasman los alegatos directos en contra del Estado chileno, provenientes desde los representantes de las comunidades williche de la isla de Chiloé. A su vez, consideramos a Chiloé como un área relevante de indagar para la comprensión de la territorialidad williche, ya que al poseer una geografía archipelágica se presenta otro modo de acercamiento al territorio, debido al entorno marítimo que caracteriza a la isla (TherRíos 2011).

A continuación se presenta el análisis obtenido por medio de las distintas interacciones discursivas con escritores, logkos y representantes williche. En una primera etapa se dilucidará el sentido de identidad expresado en los discursos orales y escritos. Posteriormente, se analizarán los discursos iconográficos de cada uno de los grupos consultados. Finalmente, se exponen las interpretaciones de los TD del pueblo mapuche-williche.

\section{Sentido territorial de escritores mapuche-williche}

\section{Ámbito estético-cultural}

Los TD de escritores williche establecen un sentido territorial conectado con la naturaleza, donde los sujetos/as permanentemente hacen alusión a mares, aves, árboles, ríos, volcanes, cohabitando sus discursos y sus experiencias territoriales e imaginarias. Este aspecto ha sido ampliamente discutido y evidenciado por las investigaciones en torno a la poesía mapuche (Carrasco 2000; García 2006; Park 2007; Mora Curriao 2018), por tanto, desde esta perspectiva, solo estamos retomando un antecedente reconocible en estudios anteriores. Sin embargo, es preciso consignarlo, pues en la posterior interpretación hologramática que realizamos, adquieren distintas formas, relieves y contornos.

Un segundo aspecto elucidado por medio de la interpretación hermenéutica de los discursos territoriales corresponde al tiempo de la infancia. Aquí la naturaleza es rememorada como una sujeta dañada por la acción del Estado chileno, existiendo un constante viaje a la memoria, donde se devela un espacio natural que ya no es el mismo al que se recuerda, retrotrayendo emociones ligadas al dolor del despojo y la remembranza de un pasado interrumpido por un antes y un después del colonialismo español y la posterior colonialidad del Estado chileno (Canales 2020).

Análogamente, se incorpora una tercera característica que irrumpe como sujeto implícito del discurso. La cosmovisión occidental y el Estado chileno se reconocen como elementos claves, adquiriendo marcas reconocibles en la memoria colectiva mapuche. Ambos sujetos si bien no son nombrados explícitamente, sí son aludidos como un otro que actúa sobre el territorio y la naturaleza.

Otro elemento clave a develar por parte de los escritores es el sentido de contradicción producido en la reflexión discursiva sobre el territorio. Aquello se manifiesta como una paradoja ocasionada por la diáspora (Brah 2011) y la frontera mestiza (Anzaldúa 1987) a la que han estado expuestos por años de discriminación y silenciamiento de la historia mapuche-williche.

Este sentido territorial corresponde a emociones contrapuestas, provocadas por el dolor causado por la colonialidad y sus diversas expresiones de discriminación racial, de clase, género y sexo (Lugones 2011), donde el proceso de autorreflexión discursivo identifica a los sujetos de fractura que modifican la relación con el territorio. Sin embargo, el dolor se imbrica con la valoración identitaria que se ha ejercido desde la resistencia mapuche (García et al. 2019), dialogando con la pertenencia cultural a una espiritualidad que resulta intocable por el pensamiento de Occidente.

\section{Mapas mentales de escritores mapuche-williche}

\section{Ámbito estético-cultural}

Para efectos de la descripción de las características desarrolladas en los TD, empleamos el registro iconográfico, donde a partir de las imágenes mentales de los territorios y utilizando algunas de las estrategias de las metodologías descolonizadas (Tuhiwai 1999), se analizan e interpretan bosquejos, dibujos y cartografías imaginarias del territorio. Es importante consignar que el punto específico al que hacemos mención cuando hablamos de principios descoloniales, consiste fundamentalmente en no hablar por los otros/as, sino que sean los propios 
sujetos de conocimiento quienes realizan la traducción e interpretación de las imágenes mentales.

A continuación se exponen dos mapas mentales del territorio mapuche-williche, los que son analizados en sus significados y relaciones por parte de los escritores williche.

Es importante señalar que el registro que se presenta es la transcripción del discurso territorial oral de los/as poetas, por lo que no quedamos exentos a la invisivilización de significados que quedan ocultos a la escritura. También es preciso destacar que el trabajo de traducción al español de palabras en mapuzugun fue realizado por Cristián Antillanca, poeta williche y conocedor de la lengua mapuche ${ }^{6}$.

\section{Memorias del territorio (1)}

Presentamos el mapa mental del territorio del grupo de escritores conformados por Graciela
Huinao, Jaime Huenún, Roxana Miranda Rupailaf, Cristián Antillanca y Bernardo Colipán:

Nuestro territorio se llama Wüñelfe que significa la primera estrella que aparece en la tarde y la última que se va en la mañana. Lo que está en medio es el Antu (sol) vinculado también con la Wïñelfe, como la estrella unificadora de lo astral. Lo que representamos (aquí) es la conjunción entre la tierra y el hemisferio sur donde estamos ahora.

En este contexto, ustedes también pueden ver lo parece un cucurucho invertido, pues ¡No lo vean así! Vean las distintas dimensiones del Mари (tierra), llámese Wente, llámese Nag, llámese Wentellao, pero acá está en relación con el otro ${ }^{7}$.

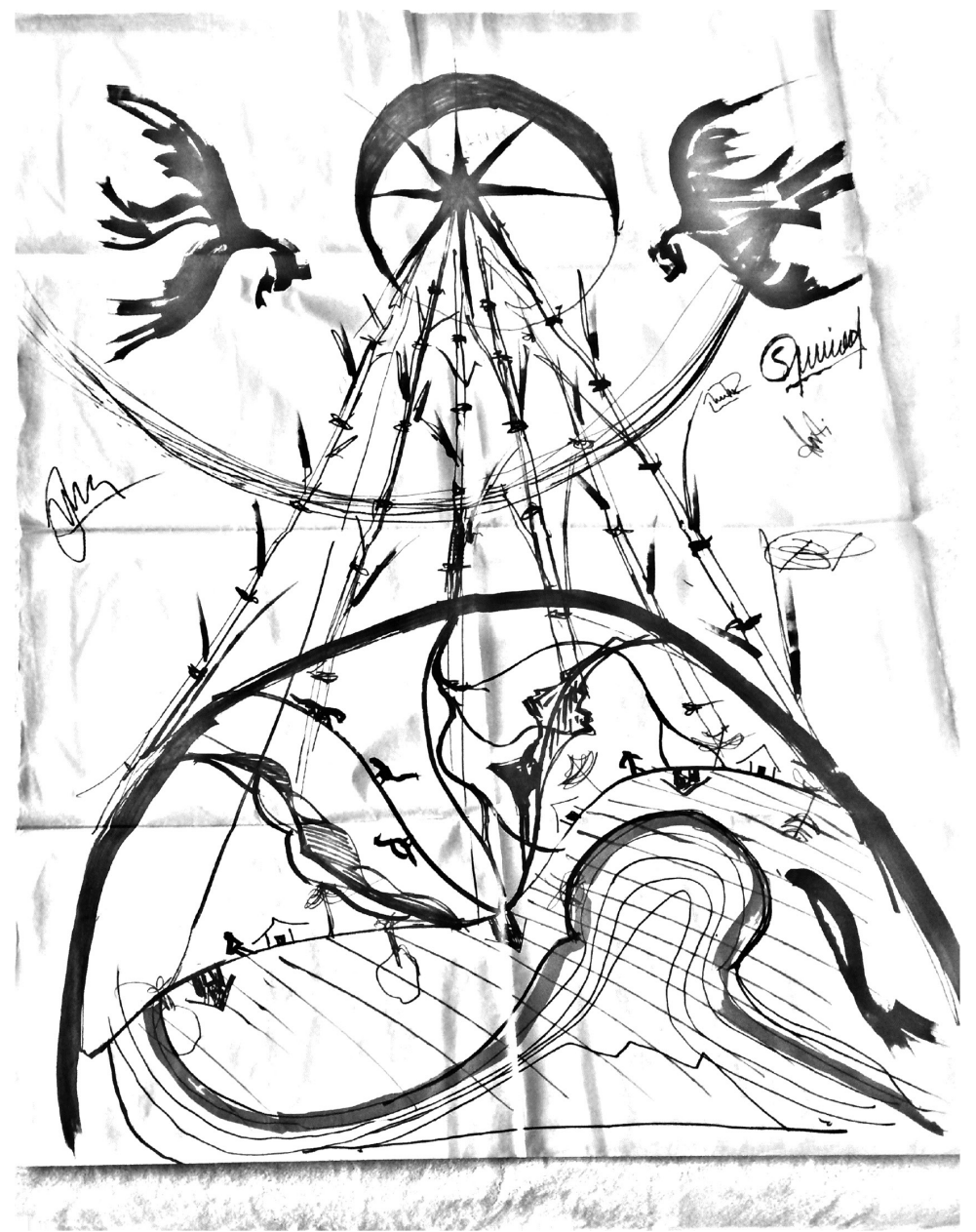

Figura I. Mapa mental de escritores williche (Huinao et al. 2017 en Antillanca et al. 2020). 
Lo anterior, es porque hay que mirar a la tierra como Nag; tenemos Lhafkenh (mar) у Мари (tierra). Esta fuerza que sostiene todo es Wentellao ${ }^{8}$.

Además, están las casas de los Peñis (hermanos), pero que se muestran en el tiempo cotidiano. También incorporamos el tiempo de la memoria, donde los rayos se transformaron en colihues.

Por otro lado, tenemos la Cordillera de Los Andes con sus respectivos pillanes (espíritus del fuego, volcanes) y la Cordillera de La Costa.

También hay una lagartija con una llama; hay un Choyke (ñandú) invertido, un Wentxu (hombre) y un Weychafe (guerrero).

Aparecen también los ríos que conectan los dos mundos, el mundo de la memoria con el mundo cotidiano, las araucarias, las manzanas, limonas y el Shumpall (espíritu del agua) que no podía faltar (Colipán 2017 en Antillanca et al. 2020).

\section{Memorias del territorio (2)}

Presentamos el segundo mapa mental realizado por el grupo de escritores formado por Faumelisa
Manquepillán, Sonia Caicheo, Miriam Torres Millán y Javier Milanca.

Quisimos representar los estratos del mundo como son: el Wenu Mapu, el Nag Mapu y el Miñche Mapu?.

Pensando en que al Nag Mapu (tierra que caminamos los humanos) le íbamos a dar toda la responsabilidad, la fuerza, la ira y el bien necesario.

De esta manera, la Waria (la ciudad) aparece como una realidad, pero también representamos Lof (comunidad mapuche), aunque principalmente la Waria.

Por otra parte, pensamos como un elemento muy importante a los volcanes, pues creemos que ellos son también un territorio, ya que siguen siendo parte fundacional de este lugar.

En otro aspecto, surge la familia y el futuro. Quisimos representar la familia con un árbol que está enraizado en la Mapu (tierra).

De esta manera, lo primero que nos expresa (el dibujo del territorio) son la presencia de los Weychafe (guerreros) muertos recientemente. Ellos están ahí en un Wепи Мари (tierra de arriba) que se hace

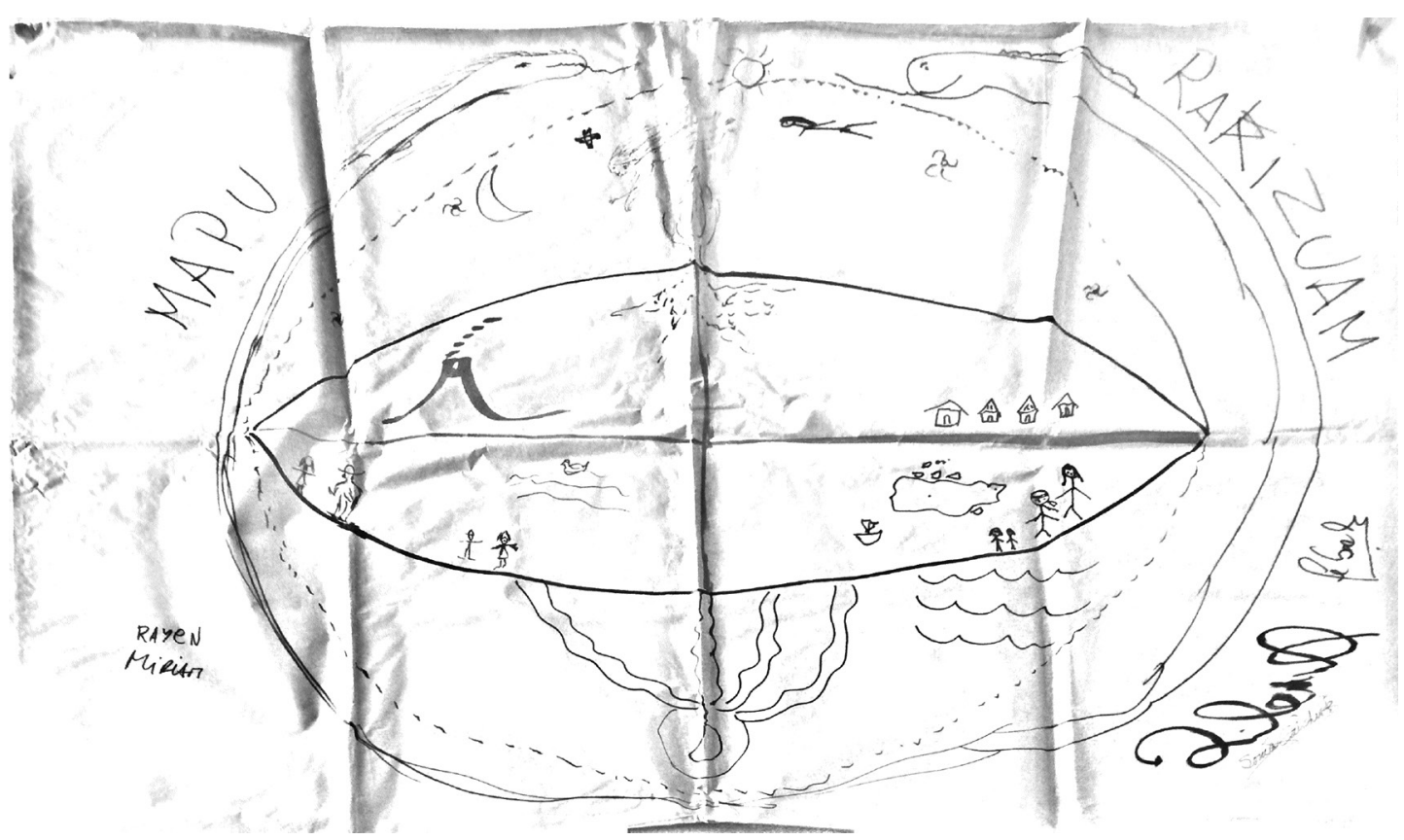

Figura II. Mapa mental de escritores williche (Manquepillán et al. 2017 en Antillanca et al. 2020). 
presente con vientos, en el alto con la Küyen (la luna).

Del mismo modo, figura un Miñche Mapu (tierra de abajo) que está con agua subterráneas que reclaman.

Hablamos también que hoy día están brotando los Ngen Ko (espíritus del agua) porque están rompiendo los caminos, están destrozando construcciones, ¡Reclamando desde abajo! En definitivas, así nos imaginamos nosotros, con Newen (fuerza espiritual) apareciendo en muchas partes y rompiendo las construcciones que se hacen ahora (Milanca 2017 en Antillanca et al. 2020).

\section{Sentido territorial de logkos mapuche-williche}

\section{Ámbito político-ancestral}

Los logkos williche develan un sentido de identidad expresado por medio de la nostalgia, desarrollando un discurso territorial colmado de referencias históricas a los modos sociales del pueblo mapuche-williche y a las transformaciones de la organización político-administrativa que han sustentado desde el pasado previo a la colonización de los españoles hasta la actualidad.

Desde las memorias de ese pasado se sitúa la afectividad expresada mediante la nostalgia, la que emerge como una característica de los TD williche, expresándose tanto discursiva como corporalmente.

Si bien este último aspecto -el cuerpo- no es parte integrante de la metodología empleada para elucidar territorios otros, consideramos relevante destacar que las afectividades atraviesan las corporalidades de los sujetos, manifestándose en los rostros, tonos, énfasis y silencios, todo ello es un espacio complejo de caracterizar, no obstante, en los discursos de los logkos se hizo particularmente evidente, pues sus expresiones corresponden a una discursividad totalmente emotiva, traspasando la posibilidad de traducción por medio de las palabras. Sin embargo, permitiéndome interpretarlas, diría que son nostalgias y dolores de una historia silenciada que se despliega en el transcurso del tiempo y los cuerpos de quienes las experimentan. Frente a esta complejidad, el objetivo se centrará, más bien, en establecer la existencia de este correlato que fluye hacia los otros/as por medio de la narrativa de sus emociones (Pihama et al. 2014).
Una de las características que surge del sentido territorial corresponde al arraigo identitario con el territorio sur, destacándose las particularidades del ser williche, donde los logkos se reconocen como parte de una cultura ancestral compartida en lo mapuche, no obstante, con ciertas especificidades identitarias a partir del territorio que habitan.

En la misma línea de análisis se encuentra el sentido circular del territorio mapuche. Los logkos expresan una conexión con la temporalidad, la que explican a base de dos conceptualizaciones:

1) La primera da cuenta de la permanente experimentación del tiempo pasado como vivencia que se presentifica en un proceso natural del curso de la memoria. Esto quiere decir que existen diferencias fundamentales entre la cultura mapuche y chilena en relación con el tiempo. Para los logkos existen posibilidades de transformación continua de los sujeto/as cuando estos rememoran su pasado como acontecimiento disponible para revisión y cambio. Este hecho es destacado por las autoridades tradicionales como una marca distintiva y trascendental para comprender las diferencias entre la cosmovisión occidental y la cultura mapuche, pues la imagen lineal del tiempo moderno impuesto a todo el planeta, donde el pasado es colocado en un espacio encriptado, imposible de modificar por su condición de acción, los hace parecer a los otros/as -en este caso a los pueblos originarios-, como sujetos ajenos e inválidos por la realidad establecida como dominante.

2) Una segunda característica corresponde a la imagen física y a la significación implícita del kultrun. Este instrumento ancestral de la cultura mapuche empleado por el/la machi en las ceremonias tradicionales, representa la circularidad de las relaciones sociales y naturales con el territorio. El kultrun se expresa como un sujeto dialógico y recursivo, ya que todas las partes que lo constituyen se encuentran interconectadas mediante la espiritualidad y la naturaleza. A su vez, las marcas que lo fragmentan en cuatro espacios diferenciados -representando los puntos cardinales del planeta y las relaciones humanas con el entorno- no pueden ser entendidos sino que al mismo tiempo, a la vez, uno dependiente del otro. 


\section{Mapas mentales de logkos mapuche-williche}

\section{Ámbito político-ancestral}

Presentamos los mapas mentales del territorio williche de los logkos Carlos Paillamanque y Arturo Camiao. Ambos autoridades tradicionales de la comuna de San Juan de la Costa. El uso de paréntesis corresponde a la traducción realizada por la investigadora.

Cuando hablamos del territorio es una visión distinta al concepto occidental de medioambiente. Va de esta forma: acá arriba está el Wenu Мapu (tierra de arriba). Esto está rodeado de todo lo que es aire. Acá estaría Nag Mapu (tierra habitada por humanos) que es lo más complicado, porque tiene muchos elementos que no se ven.
Por otra parte, lo que la gente ve como las montañas, el mar, ese es el Lhafkenh. Acá siguen los Мари (las tierras), por ejemplo el Puel Mapu (tierra del este) y el Pikun Mapu (tierra del norte) у Willi Mapu (tierra del sur). Entonces el territorio es lo que da esta vuelta. Por eso nuestra espiritualidad está basada también en esta cosmovisión. Aquí necesariamente está el Kuruf que es el aire, parte del cielo -lo que la gente le dice lo azul-, ese sería como el Wenu Мари (tierra de arriba) que también tiene muchos elementos que no se ven. Aquí también hay harta espiritualidad y en todas estas partes hay vida. Es como la $\tilde{N} u k e$ Мари (la madre naturaleza) que no está separada en recursos como lo piensan los medioambientalistas que dicen acá está el Lhafkenh (el mar); acá está Mawiza

$$
\text { WENU MAPU }
$$

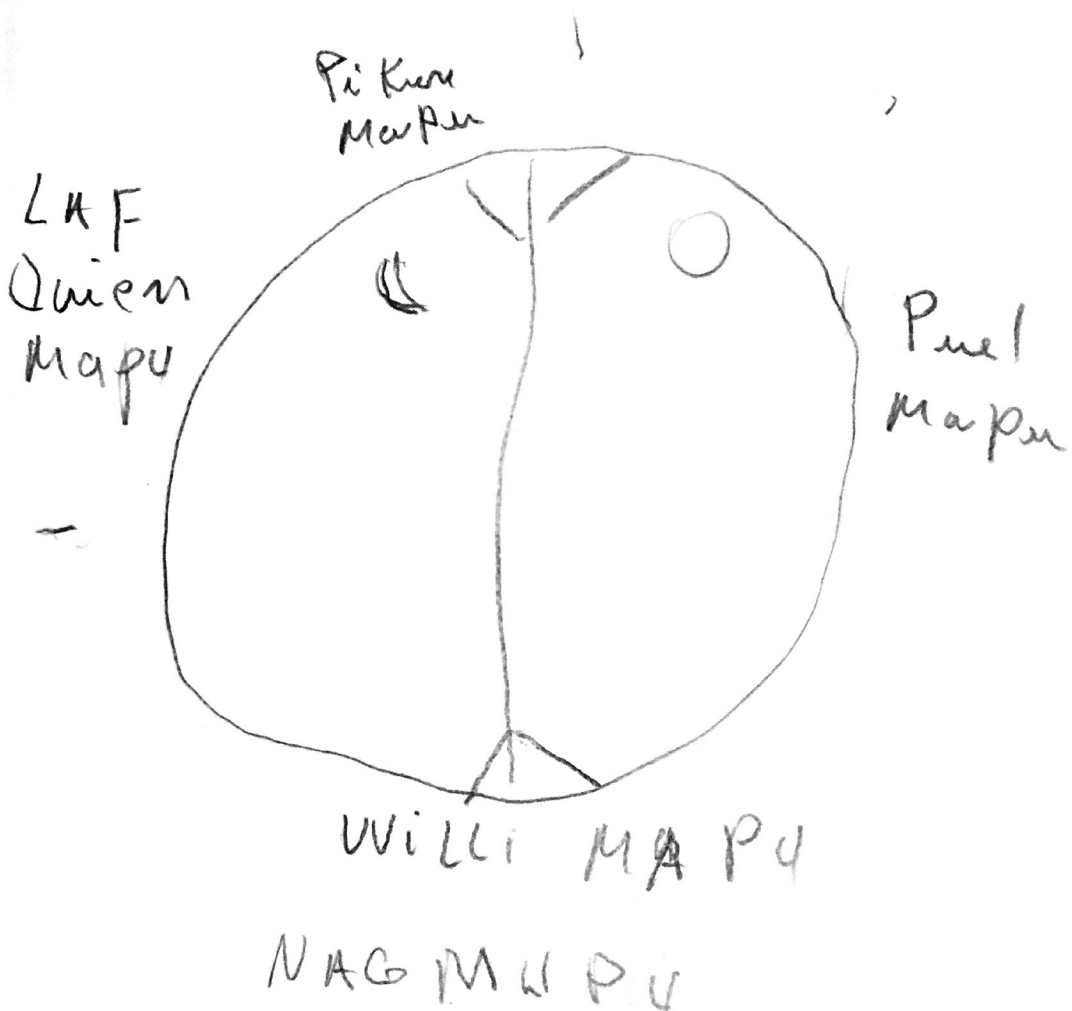

Figura III. Mapa mental de logkos williche (Paillamanque 2019). 
(monte o montaña) y lo van separando. Separan el territorio y separan al che (gente) (Carlos Paillamanque comunicación personal 2019).

El espacio celeste es el Wenu Mapu-lo que le dicen el cielo-. Por debajo el español le dice el subsuelo y nosotros le decimos Miñche Mapu (tierra de abajo). También está el Nag Mapu (lugar habitado por los seres humanos), el que está habitado por un sin número de seres. ¡No es un espacio muerto! también hay vida. Por ejemplo, están los minerales que están por debajo y están las fuerzas por otro lado. Entramos por el concepto espiritual, están las fuerzas malignas o fuerzas del mal o Weza Newen. Y por aquí en el espacio celeste están las fuerzas del bien como el Newen (energía o fuerza espiritual).

Aquí está la forma de pensar cíclicohorizontal y renovable. La forma cómo se desarrolla, cómo funciona esa filosofía es el Rakizuam, el conocimiento del pasado y eso es lo que circula.

Esto mismo se refleja cuando se conmemora el Wüñol Txipantu -el año nuevo-. Porque la tierra sabemos que da una vuelta al transcurso de un año y parte desde aquí del Puel Мари (tierra del este).

Acá tenemos lo que es la visión de la cultura occidental, recto, horizontal. ¡Cómo se desarrolla en función de apoderarse de todos los recursos que la naturaleza tiene! ahí no existe el Nag Mapu .

Entonces todo eso es parte del territorio, no solo la tierra que uno pisa. Es tremendamente complejo poder graficar y mostrarlo. Pero a través del tiempo, en conversaciones como estas servirá, en un tiempo (Arturo Camiao comunicación personal 2019).

\section{Sentido territorial de representantes williche de Chiloé}

\section{Ámbito político-representativo}

Los discursos que analizaremos en este apartado corresponden a la transcripción y síntesis que realizó el/la facilitadora intercultural encargado/a de redactar las actas de las consultas indígenas. Los documentos fueron aprobados por los intervinientes williche con la firma de quienes son nombrados para estos efectos.

El total de participantes de las cinco actas analizadas fue de ochenta y un intervinientes de las localidades de Quinchao, Castro, Chonchi, Quellón y Quenchi. Este proceso se llevó a cabo entre noviembre y diciembre de 2016 por parte del Ministerio de Desarrollo Social durante el segundo gobierno de Michelle Bachelet.

El propósito de la consulta era interrogar a las comunidades originarias acerca de sus principales demandas para dar inicio a un proceso constituyente que determinaría la redacción de una nueva Constitución política. Intencionalidad que no prosperó con el siguiente mandato presidencial dirigido por Sebastián Piñera, actual Presidente de Chile, quien solo frente a un multitudinario estallido social iniciado el 18 de octubre de 2019, se propuso, en conjunto con partidos políticos de distintos sectores, un denominado acuerdo por la paz. Lo anterior, con el objetivo de convocar a un plebiscito que estableciera la posibilidad de redacción de una nueva constitución efectivamente escrita en democracia. Dicho acontecimiento finalmente se llevó a cabo el 25 de octubre de 2020 , donde se obtuvo $78,3 \%$ de las preferencias a la opción que aprueba una nueva Constitución. Actualmente, los pueblos originarios cuentan con 17 escaños reservados para asegurar su inclusión en este proceso.

En adelante, presentamos el análisis de los aspectos territoriales que emergen de estos discursos.

Los intervinientes de las actas del proceso constituyente indígena aluden a un sentido territorial que coloca énfasis en las capas internas del territorio mapuche, expresando una conexión identitaria con el subsuelo marino y terrestre, característica que se traduce en una marca significativa dentro de sus discursos.

Dicha conexión ha sido puesta en conflicto, debido al actuar negligente por parte del Estado chileno y de la cosmovisión occidental que coloca un valor económico a territorios vinculados con culturas originarias, negando la importancia del cuidado y protección de estos (Tricot 2013).

Los discursos de los representantes williche refieren directamente a la vivencia archipelágica de los habitantes de la isla de Chiloé. En este contexto, el tópico del agua es recurrente, al mismo tiempo que surge la preocupación por el subsuelo terrestre y del fondo marino, a causa de la permanente 
contaminación provocada por empresas acuícolas y salmoneras principalmente (Buschmann 2005; Álvarez et al. 2019).

Al respecto, el reclamo que se desprende de las actas apunta a que el Estado chileno conocería de la riqueza material del subsuelo y por lo mismo lo explota y contamina sin restricciones, pues desde la óptica extractivista aplicada por los distintos gobiernos, hay que obtener el mayor provecho económico posible, sin resguardar aspectos simbólicos considerados como irrelevantes como son las identidades indígenas y las conexiones vivas con la naturaleza. De esta manera, las identidades williche surgen como tópico de oposición a la racionalidad occidental de explotación y contaminación de las capas internas de los distintos territorios.

Otra característica emerge del vínculo de una memoria histórica-política entre el Estado chileno y el pueblo mapuche. Aquello se materializa en el reclamo por los tratados y convenios nacionales e internacionales firmados para proteger el respeto y soberanía de los pueblos indígenas. Desde este punto, surge la indicación directa al expresidente -de la época- Sebastián Piñera por la compra del Parque Tantauco.

Por consiguiente, podemos evidenciar en el análisis de sus discursos un sentido territorial estrechamente ligado a lo político, lo que se debe al rol que cumplen los representantes indígenas al entablar un diálogo con el Estado, toda vez que han identificado la necesidad de incorporar los códigos que emplean los diferentes gobiernos para despojarlos de sus territorios.

En este aspecto, también hay un reconocimiento a la falta de información y al manejo de leyes, recursos y procedimientos que deben realizar para interactuar con los organismos estatales, reconociéndose como sujetos/as en desventaja para la recuperación política del territorio mapuche. Con otras palabras, desde la dirigencia williche se plasma un sentido territorial en construcción identitaria, debido a que parte de sus discursos de redistribución territorial se sustentan en métodos y estrategias provenientes desde la lógica occidental -como por ejemplo, las políticas propiciadas por la Corporación Nacional de Desarrollo Indígena CONADI-, no logrando aún subvertir del todo los sentidos hegemónicos presentes en la discusión estatal. Pese a ello, se evidencia un esfuerzo importante por colocar en tensión las significaciones de dos conceptos claves: 1) lo político y 2) lo institucional.
Este proceso de subversión consiste en incorporar a la memoria histórica como parte fundamental de la interacción con el Estado, intentando doblegar el poder que ha negado los trayectos coloniales que atraviesan la historia de Chile. Esta estrategia consiste en la intromisión permanente en actos de reivindicaciones identitarias, relatos de desterritorialización material y simbólica ejercidos por el Estado chileno, como por ejemplo, la restitución del parque Tantauco al dominio de comunidades originarias williche.

Como contraparte, estos discursos de reivindicación territorial son desestimados por la institucionalidad estatal como intervenciones irrelevantes para el avance del diálogo político, sin embargo, son considerados fundamentales por parte de las comunidades williche para la construcción de una narrativa política de real reconocimiento cultural y justicia socioterritorial.

\section{Territorios discursivos del pueblo mapuche-williche}

Desde el estudio de los discursos territoriales williche podemos identificar variadas marcas discursivas que configuran las imágenes mentales de los TD.

Es importante destacar que no es posible vislumbrar un territorio único y homogéneo para los tres registros discursivos interpretados - escritores, logkos y representantes-. No obstante, sí existen lugares comunes donde se encuentran líneas identitarias y afectivas, ligadas principalmente a la memoria y al Rakizuam (reflexión o pensamiento mapuche).

Desde estas imágenes y sentidos obtenidos a partir de la interpretación de los discursos, podemos caracterizar los TD por medio de cuatro estructuras de significación que dan forma y figuras concretas a los hologramas territoriales williche. Estas son:

\section{1. Ámbito visual}

Una de las particularidades principales de los TD es su capacidad hologramática que redunda tanto en el paradigma de la complejidad (Morin 1999) como en la visualidad que los constituye en imágenes colectivas en constante movimiento (Villanueva-Gallardo 2019a). En este sentido, los TD williche se caracterizan visualmente por una diversidad de componentes, entre los que podemos nombrar: fuego, ríos, mares, volcanes, carbón, 
árboles, animales y colores difuminados entre lo urbano y lo rural.

Cada uno de estos aspectos se instala en el paisaje imaginativo actual de el/la williche que articula un discurso territorial identitario, estableciendo un espacio que se asemeja más al caos que al orden de la lógica instrumental, ya que los sentidos afectivos están intercalando constantemente estas imágenes, modificándolas en sus colores y formas, haciendo más predominantes unos elementos sobre otros, dependiendo de las circunstancias colectivas en que cada discurso territorial es articulado.

Por ejemplo, en el registro de los/as escritores williche, los volcanes son una marca encendida que otorga visualidad y sonoridad a los TD. En comparación al ámbito político-ancestral expresado por los logkos, quienes hacen predominar las figuras de los animales y la circularidad de las fronteras. Por otro lado, los representantes williche de Chiloé otorgan un lugar central al agua en todas sus formas, ríos, mares y aguas subterráneas. A pesar de estas distinciones, en cada colectividad operan con mayor o menor presencia estos aspectos visuales del territorio.

Es posible destacar que los árboles de los TD williche corresponden a un tipo de habitante de doble significación. Por una parte, son un elemento vivo de la naturaleza, de la fuerza originaria e interconectada con la espiritualidad y, por otra, actúan como humanidades que están arraigadas al espacio y al territorio. Es decir, en vez de personas corporalizadas, los habitantes son árboles situados unos al lado de los otros, como representación de la colectividad nuclear, del Lof, familia o Muchulla.

\section{2. Ámbito auditivo}

Los TD mapuche-williche son hologramas acústicos, contrarios a una fotografía del territorio que puede plasmar características estáticas y en pleno silencio. Ellos visibilizan la vivencia auditiva experimentada desde la epistemología mapuche, quien entiende la relación compleja con el territorio y con los sentidos interconectados a la naturaleza. Este espacio se traduce en diferentes sonidos, entre los que podemos nombrar: el canto de las aves, el sonido del mar, el ruido de la urbanidad, el crispar del fuego, gritos humanos y de seres vivos, incluida la naturaleza como fuerza viva que reclama y dialoga con sus habitantes.

En este escenario se vuelve a reproducir la categoría de caos, ya que los diversos sonidos no están completamente individualizados, sino más bien entre todos conforman un nuevo espacio acústico de características recursivas con la visualidad, es decir, que se dan al mismo tiempo y se distinguen de otras colectividades originarias.

\section{3. Ámbito simbólico}

Dentro de la materialidad visual y auditiva de los TD williche existe una fuerza simbólica que actúa en todo momento en la configuración hologramática del territorio. Nos referimos a que hay una marca histórica ineludible en los discursos territoriales mapuche, una herida colonial -diría Anzaldúa-, que no es posible describir sin mencionar el dolor del despojo y la nostalgia ocasionada por una historia genocida a manos de la empresa colonial española y del posterior actuar del Estado chileno (Colipán 2012; Castillo y Ramírez 2018).

Partiendo desde este punto de la memoria histórica, los TD mapuche-williche se configuran a partir de los siguientes símbolos: la fractura del territorio ancestral mapuche, la memoria actuando como nostalgia de un pasado dañado, la subversión de conceptos hegemónicos empleados por Occidente, el dolor del despojo y la autorreflexión permanente sobre el territorio.

Cada una de estas marcas actúa como un magma de significaciones internas (Castoriadis 1997), dando un sentido específico a los discursos, modificando las imágenes mentales del territorio williche.

\section{4. Ámbito frontera}

Finalmente, nos encontramos con los límites de estos territorios, con la posibilidad de explicar ¿hasta dónde llegan los TD mapuche-williche? La respuesta a aquello está enmarcada en el conocimiento ancestral mapuche impregnado en las concepciones imaginarias sobre el territorio. Nos referimos a que las fronteras de estos TD no corresponden a un espacio plano y recto, sino a un tipo de territorio que presenta distintas capas subterráneas, espirituales y colectivas.

En este entendido, las características sintetizadas de la frontera discursiva williche se asienta en márgenes circulares, fronteras que colindan consigo mismas y donde el Estado chileno y el pensamiento occidental actúan como sujetos tácitos de una escisión territorial.

La frontera discursiva de las comunidades williche se erige como un camino posible para la 
reconstrucción de territorios dañados fuertemente por el colonialismo, porque a pesar de todo el despojo, del genocidio y la actual discriminación y segregación territorial, los TD mapuche-williche se configuran desde sus propios márgenes, sin ubicar marcadamente al otro, dejando a Occidente y al Estado chileno en un espacio secundario, presente, pero no predominante.

En consecuencia, estamos frente a una frontera identitaria que no ha sido corrompida por el dolor, sino reconstruida por los sentidos afectivos que producen, dando la posibilidad cierta a un diálogo intercultural por medio de la valoración de la naturaleza, el territorio y el habitante.

\section{Conclusión}

Los TD del pueblo mapuche-williche son espacios diversos, habitados por seres, creencias, símbolos y emociones conectadas por medio de la cultura mapuche. Esta realidad hologramática de características imaginarias, condiciona los discursos que emergen desde la colectividad, evidenciándose como una experiencia desplegada en el territorio. Dicho de otro modo, cada vez que se articula un discurso identitario sobre el territorio mapuchewilliche se está apelando inconscientemente a estas imágenes, pudiéndose conservar o modificar sus significaciones.

En este escenario, las restricciones teóricas subyacentes a la desigual realidad que han vivido los pueblos originarios en Chile, también son parte significativa del proceso de descolonización. Por tanto, la ciencia también cumple un rol en este tránsito, siendo un objetivo transversal de este estudio, apuntar hacia un horizonte que permita co-construir mejores prácticas discursivas acerca de cómo se conforman y se habitan los distintos territorios.
Lo anterior se presenta como una posibilidad concreta de comenzar a vislumbrar otras maneras de ser y estar, iniciando un camino político y constitucional que realmente integre y valore las experiencias territoriales simbólicas, ya que estas se viven con un profundo sentido de identidad y verdad.

A modo de término abierto, finalizamos con las palabras de Faumelisa Manquepillán -poeta williche que participó activamente como sujeta de conocimiento dentro de esta investigación-, quien sintetiza de forma íntegra el sentido profundo que emerge desde esta frontera, por medio del relato perteneciente a su discurso territorial, donde enfatiza cómo la resistencia mapuche emerge desde un lugar distinto, desde un territorio otro, invitándonos a creer que no solo otro mundo es posible, sino que ese mundo está actuando desde las conexiones identitarias de cada pueblo.

(a pesar de todo ${ }^{10}$ ) "el círculo está intacto" (Manquepillán 2017 en Antillanca et al. 2020).

\section{Agradecimientos}

Este artículo es parte de la tesis doctoral de mi autoría "Fundamentos teóricos metodológicos de los territorios discursivos: Estudio en los discursos territoriales Mapuche y del Estado chileno actual" financiada por becas de doctorado nacional ANID y por la Dirección de Postgrado de la Universidad de Los Lagos. Agradezco a cada uno/a de los/as escritores, logkos y representantes williche que fueron parte de esta investigación. A los/as académicos/as Adela Franzé, Rossana Cassigoli, James Park, Nelson Vergara y Francisco Ther por sus comentarios y recomendaciones a este trabajo.

\section{Referencias Citadas}

Álvarez, R., Ther-Ríos, F., Skewes, J C., Hidalgo, C.

2019 "Reflexiones sobre el concepto de maritorio y su relevancia para los estudios de Chiloé contemporáneo". Revista Austral de Ciencias Sociales 36:115-126.

Antileo, E.

2015 "Trabajo racializado. Una reflexión a partir de datos de población indígena y testimonios de la migración y residencia mapuche en Santiago de Chile". Meridional Revista Chilena de Estudios Latinoamericanos 4:71-96.
Antillanca, C., Caicheo, S., Colipán, B., Huenún, J., Huinao, G., Manquepillán, F., Miranda Rupailaf, R., Torres Millán, M. 2020 La otra Resistencia: Antología Territorial de Escritores Mapuche-Williche. Pehuén Editores y CIIR, Chile.

Anzaldúa, G.

1987 Borderlands/La Frontera: The new Mestiza. Spinster/ Aunt Lute, San Francisco.

Bacigalupo, A.

1997 "Las múltiples máscaras de Ngünechen: las batallas ontológicas y semánticas del ser supremo Mapuche en Chile". Journal of Latin American Lore 1:173-204. 
Brah, A.

2011 Cartografías de la Diáspora. Identidades en cuestión. Traficantes de sueños.

Buschmann, A.

2005 "Marea roja y salmonicultura en el sur de Chile". Publiciones Oceana, 14.

Calfío, M.

2017 "Weychafe zomo. Mujeres mapuche: Resistencias, liderazgos y vocerías en dictadura". Revista Anales 13:263-281.

Canales, $\mathrm{P}$.

2020 "La división de las tierras mapuches en la reducción Gallardo Tranamil, 1979-1985”. Diálogo Andino 61:93-103.

Carrasco, I.

2000 "Poesía mapuche etnocultural". Anales de Literatura Chilena 1:195-214.

Castillo, M y Ramírez, C.

2018 Violencia Estatal contra la mujer Mapuche. Transdono ediciones, Osorno.

Castoriadis, C.

1997 El Imaginario social Instituyente. Zona Erógena. № 35.

Cayuqueo, $\mathrm{P}$.

2017 La Historia Secreta Mapuche. Catalonia, Santiago.

Claverías, A., Vergara, J., Gundermann, H.

2020 "Territorio y violencia en las comunidades mapuches de la provincia de Arauco (siglo XX). Una reconstrucción desde la historia oral”. Diálogo Andino 61:105-125.

Colipán, B.

2012 Forrahue. Matanza 1912. CONADI, Osorno.

Coordinadora Arauco Malleco (CAM)

2019 Chem ka Rakiduam.

Corporación Nacional de Desarrollo Indígena CONADI

2005 Azümchefe hacia la Escritura del Mapuzugun. Potencialidad Lingüística del Grafemario Azümchefe. CONADI, Chile.

García, M.

2006 "El discurso poético mapuche y su vinculación con los 'temas de resistencia cultural"". Revista chilena de literatura 68:169-197. https://dx.doi.org/10.4067/ S0718-22952006000100007

García, M., Caniuqueo, S., Foote, S., Park, J.

2019 "Pueblo Mapuche. La representación de la nación a través de la producción discursiva en el Gulumapu". Anclajes (23)2:1-20.

Giménez, G.

1999 "Territorio, Cultura e Identidades. La región sociocultural". Estudios sobre las Cultura Contemporáneas 9:25-57.

Guattari, F.

2013 Líneas de fuga. Por otro mundo de Posibles. Cactus, Buenos Aires.

Lindón, A.

2007 "Los Imaginarios Urbanos y el constructivismo geográfico: los hologramas espaciales". Revista Eure 99:31-46.

Lugones, $\mathrm{M}$.

2011 "Hacia un feminismo descolonial". La manzana de la discordia (6) 2:105-119.

Mallon, F.

2004 La sangre del Copihue. La Comunidad Mapuche de Nicolás Ailío y el Estado Chileno 1906-2001. LOM Ediciones, Chile.
Marimán, P.

1997 "La Diáspora Mapuche: una reflexión política". Liwen (4).

Mora Curriao, M.

2018 "Muestra de poesía mapuche. Trazas poéticas sobre una cartografía indígena incesante". Anales de la Universidad de Chile 13:165-218.

Morin, E.

1996 Introducción al Pensamiento Complejo. Gedisa, Barcelona.

Morin, E.

1999 La Cabeza bien puesta: Repensar la Reforma, Reformar el Pensamiento. Ediciones Nueva Visión, Argentina.

Nahuelpán, H.

2012 "Formación colonial del Estado y desposesión en Ngulumapu". Ta iñ fijke xipa Rakizuameluwün. Historia, Colonialismo y Resistencia desde el país Mapuche, eds., H. Nahuelpán, H. Huinca, P. y L. Cárcamo-Huechante. 119-152. Ediciones Comunidad de historia mapuche, Temuco.

Pairican, F.

2015 "Autodeterminación de los pueblos originarios. Una lucha por conquistar derechos civiles". Le Monde Diplomatique 6-7. https://www.comunidadhistoriamapuche.cl/wp-content/ uploads/2016/06/Una-lucha-por-conquistar-derechos.pdf

Park, J.

2007 "Discursos y poética mapuche-huilliche actual: Cambio generacional y diferencia territorial". Alpha 24:139-162.

Pihama, L., Reynolds, P., Smith, C., Reid, J., Smith, LT., Nana, RT.

2014 "Positioning Historical Trauma Theory within Aotearoa new Zealand". AlterNative: An International Journal of Indigenous Peoples 10 (3):248-262. doi:10.1177/117718011401000304

Pinto, J.

2015 Conflictos Étnicos, Sociales y Económicos Araucanía 1900-2014. Pehuén Editores, Chile.

Quintriqueo, S. y Arias-Ortega, K.

2019 "Educación Intercultural Articulada a la Episteme Indígena en Latinoamérica. El caso Mapuche en Chile". Diálogo Andino 59: 81-91.

Ther-Ríos, F.

2011 "Configuraciones del Tiempo en el Mar Interior de Chiloé y su relación con la apropiación de los Territorios Marítimos". Desenvolvimento e Meio Ambiente 23:67-80.

Tricot, $\mathrm{T}$.

2009 "El nuevo movimiento mapuche: hacia la (re)construcción del mundo y país mapuche". Revista de la Universidad Bolivariana 8:175-196. http://dx.doi.org/10.4067/ S0718-65682009000300010

Tricot, T.

2013 Autonomía. El Movimiento Mapuche de Resistencia. Ceibo Ediciones, Santiago.

Tuan, Y. F.

1974 Topophilia: A Study of Environmental Perception, Attitudes and values. Prentice-Hall Inc. Englewood Cliffs, New Jersey.

Tuhiwai, L.

1999 Decolonizing Methodologies research and Indigenous peoples. Zed Books Ltd, London \& New York.

Vergara, J. y Mellado, H.

2018 "La violencia política estatal contra el pueblo-nación mapuche durante la conquista”. Diálogo Andino 55:5-17. 
Villanueva-Gallardo, S.

2018 "Fundamentos teóricos epistemológicos de los territorios discursivos". Cinta de Moebio. Revista de Epistemología de Ciencias Sociales 62:221-230. 10.4067/S0717-554X201 8000200221

Villanueva-Gallardo, S.

2019a "Aproximación metodológica al concepto de territorios discursivos". Diálogo Andino 59:55-63. http://dx.doi. org/10.4067/S0719-26812019000200055
Villanueva-Gallardo, S.

2019b "Fundamentos metodológicos de los territorios discursivos". Cinta de Moebio. Revista de Epistemología de Ciencias Sociales 63:357-364. 10.4067/S0717- 554X2018000 300357

Zapata, C.

2005 "Origen y función de los intelectuales indígenas". Cuadernos interculturales 3:65-87. https://www.redalyc. org/articulo.oa? $\mathrm{id}=55200406$

\section{Notas}

1 Entendemos por holograma aquella manifestación territorial producida por el imaginario colectivo, la que es expresada por medio de los discursos (Lindón 2007). A su vez, dice relación con uno de los postulados del paradigma de la complejidad de Edgar Morin (1996).

2 Para efectos de este estudio, entendemos por territorio una construcción social compleja, asociada a las prácticas cotidianas y culturales de los/as sujetos (Giménez 1999). Por discurso territorial, entendemos todas aquellas manifestaciones orales, escritas e iconográficas que refieren acerca de un territorio en particular (Villanueva-Gallardo 2019b).

3 La Fütawillimapu comprende una parte del territorio ancestral mapuche que abarca desde el río Toltén por el norte, hasta el seno de Reloncaví por el sur, circunscrito actualmente a las regiones de La Araucanía, Los Ríos y Los Lagos en el sur de Chile. A la vez, la Fütawillimapu forma parte del Wallmapu (gran territorio mapuche), el que ha existido originariamente en ambos lados de la cordillera de los Andes, tanto en Chile como en Argentina (Tricot 2009).

4 Designamos la categoría estético-cultural para referir a los escritores williche, ya que la comprensión territorial que ellos/as propician, exceden con creces el ámbito literario, abarcando aspectos estéticos del paisaje y elementos profundos acerca de la cultura originaria.

5 Los nombres de logkos y escritores que figuran en esta investigación han sido autorizados a ser nombrados por los propios sujetos de conocimiento.

6 Las palabras del mapuzugun que figuran en este artículo responden al grafemario Azümchefe (CONADI 2005). Además, contamos con la colaboración en la traducción del poeta williche Cristián Antillanca.

7 Esta idea hace referencia a la conformación del universo mapuche y sus diferentes estratos, donde están los tres elementos que en la cultura occidental se entenderían como el cielo, la tierra y el subsuelo, pero que en la cosmovisión mapuche tienen otra esfera de entendimiento por ser espacios vivos y repletos de espiritualidad.

8 Hace mención al abuelito Wentellao, el que corresponde a una divinidad del pueblo mapuche-williche.

9 Se refiere a la descripción de los estratos del territorio mapuche: Wenu Mapu/Tierra de arriba. Nag Mapu / Tierra en la que caminamos y Miñche Mapu / Tierra de abajo o subsuelo.

10 Paréntesis de la investigadora. 